Tropical Journal of Pharmaceutical Research October 2012; 11 (5): 759-765

(C) Pharmacotherapy Group,

Faculty of Pharmacy, University of Benin

Benin City, 300001 Nigeria

All rights reserved.

Available online at http://www.tjpr.org

http://dx.doi.org/10.4314/tjpr.v11i5.9

Research Article

\title{
Effect of Bridelia ferruginea (Euphorbiaceae) Leaf Extract on Sucrose-induced Glucose Intolerance in Rats
}

\author{
Dieudonne Njamen ${ }^{1}$, Benedicta $\mathbf{N}$ Nkeh-Chungag ${ }^{2}$, Emmanuel Tsala ${ }^{3}$, \\ Zacharias T Fomum ${ }^{3}$, Jean Claude Mbanya ${ }^{4}$ and George F Ngufor ${ }^{5}$ \\ ${ }^{1}$ Department of Animal Biology and Physiology, Faculty of Science, University of Yaounde1, PO Box 812, Yaoundé, \\ Cameroon, ${ }^{2}$ Department of Zoology, Faculty of Science, Engineering and Technology, Walter Sisulu University, \\ Mthatha, 5117, South Africa, ${ }^{3}$ Department of Organic Chemistry, Faculty of Science, University of Yaoundé 1, PO \\ Box 812 Yaoundé, ${ }^{4}$ Department of Internal Medicine, Faculty of Medicine and Biomedical Sciences, University of \\ Yaounde1, ${ }^{5}$ Department of Health, Yaoundé, Cameroon.
}

\begin{abstract}
Purpose: To evaluate the hypoglycaemic effect of the methanol extract of Bridelia ferruginea leaves (MEBF) on sucrose-induced glucose intolerance in rats.

Methods: Male Wistar rats, aged 6 - 7 weeks and weighing $140-160 \mathrm{~g}$, were used. The animals were fed standard rat chow supplemented with $35 \%, 50 \%$ or $65 \%$ sucrose for 8 weeks while control animals were fed standard rat chow. The hypoglycaemic effect of MEBF and the reference drugs (tolbutamide, and metformin) in the animals were evaluated following a single dose of these drugs and 6-day treatment. Plasma lipid profiles were also determined.

Results: Fasting glucose concentrations ranged from 45 to $70 \mathrm{mg} / \mathrm{dl}$, and the increase was significant in the sucrose diet groups from week 1. After 2 weeks on these diets, oral glucose tolerance test showed that sucrose feeding significantly impaired glucose homeostasis 1 and 2 hours after a glucose challenge (76.7 \pm 2.0 versus $86.4 \pm 8.5$ and $66.7 \pm 1.4$ versus $75.5 \pm 3.0$, respectively). Fasting blood sugar levels were significantly $(p<0.05)$ reduced in sucrose-induced, glucose-intolerant rats after a single dose of MEBF. The extract also significantly reduced blood glucose (from $167 \pm 23 \mathrm{mg} / \mathrm{dL}$ to $126 \pm 5$ $\mathrm{mg} / \mathrm{dL}$ ), serum total cholesterol (from $161 \pm 20 \mathrm{mg} / \mathrm{dL}$ to $93 \pm 10 \mathrm{mg} / \mathrm{dL}$ ) and triglyceride levels (281 \pm 25 $\mathrm{mg} / \mathrm{dL}$ to $228 \pm 5 \mathrm{mg} / \mathrm{dL}$ ) in glucose intolerant rats after 6 days of treatment.

Conclusion: The methanol leaf extract of Bridelia ferruginea exhibited hypoglycaemic effect in glucoseintolerant rats.
\end{abstract}

Keywords: Sucrose-induced, Glucose intolerance, Bridelia ferruginea, Hypoglycaemia, Metformin, Tolbutamide. 


\section{INTRODUCTION}

Diabetes mellitus is one of the most common endocrine and metabolic disorders affecting over 170 million people worldwide $[1,2]$. Insulin resistance is a key phenomenon in the pathogenesis of type 2 diabetes and is usually associated with the obesity, dyslipidaemia and hypertension. Insulin resistance, characterised by hyper-insulinemia, hypertriglyceridemia and hypertension, has been reported in primary normoglycaemic and normotensive, genetically non-susceptible Sprague-Dawley rats fed high sucrose or fructose diets [3,4]. Increased fructose consumption, on the other hand, has been associated with obesity epidemic as well as metabolic syndrome [5,6]. Fructose-rich and high fat diets, commonly consumed in emerging urban areas, has been associated with increased prevalence of overweight/obesity and diabetes in these communities [7].

Among the many challenges faced by developing countries in the face of rapid urbanization is the need for medications to address emerging diseases such as diabetes mellitus. To address this need, indigineous knowledge is often referred to, including the use of extracts from medicinal plants. Several plant extracts are reported to have hypoglycaemic effect including Bridelia ferruginea (Euphorbiaceae) [8] - a woody shrub which grows in the Savannah or rain forests of Africa. Traditionally, B. ferruginea bark extract is used as a milk coagulant, mouth wash, purgative and vermifuge. It is also used for the treatment of diabetes, arthritis and boils. Extracts of the plant have been shown to have molluscidal effect [9], antibacterial activity [10], anti-inflammatory property [11] and hypoglycaemic effect [12]. Several compounds with cytotoxic and cytostatic activity on tumor cell lines, such as $\beta$-peltatin-5-O- $\beta$-D-glucopyranoside, deoxypodophyllotoxin and 5 'demethoxy- $\beta$-peltatin$5-O-\beta-D$-glucopyranoside, have been isolated from $B$. ferruginea [13]; so also is the biflavanol gallocatechim-[4-O-7]-epigalloca- techim [14]. Although this plant extract has been shown to have hypoglycaemic effect, its effect has not been studied in sucroseinduced glucose intolerance. The objective of the present study was, therefore, to induce glucose intolerance in normal Wistar rats using sucrose loading and to investigate the hypoglycaemic effect of the methanol leaf extract of Bridelia ferruginea in the rats.

\section{EXPERIMENTAL}

\section{Plant material}

Bridelia ferruginea was collected in May 2000 in Yaoundé - Cameroon. It was identified and authenticated by Mr Nana, a taxonomist at the Cameroon National Herbarium in Yaoundé where a voucher specimen (32266/HNC) was deposited. Air-dried and powdered leaves $(1 \mathrm{~kg})$ were extracted with methanol at room temperature for $72 \mathrm{~h}$ followed by evaporation of the solvent under reduced pressure using a Büchi Rota-vapor (Bioblock, Illkirch-France). A greenish crude extract $(80 \mathrm{~g})$ was obtained, from which test solutions of the required concentrations were prepared in Tween 80/ethanol/water (1:1:10) for subsequent evaluation.

\section{Drugs}

Tolbutamide and metformin, used in these experiments were obtained from Norvo Nordisk.

\section{Experimental animals}

Six to seven week-old male Wistar rats, weighing $140-160 \mathrm{~g}$, were used in these experiments. Housing of animals and all in vivo experiments were carried out following the guidelines of the Institutional Ethics Committee of the Cameroon Ministry of Scientific Research and Technology Innovation, which has adopted the guidelines established by the European Union on Animal Care (CEE Council 86/609EEC, EMBO, 2005) [15]. 


\section{Induction of glucose intolerance}

At the start of the experiment, baseline fasting blood glucose level was determined for all animals after a 12-h fast. A spectrophotometer, Hemocue ${ }^{R}$ B-Glucose Analyser (Angelholm, Sweden), was used to measure blood glucose levels in whole capillary blood obtained by puncturing the tail vein. Animals with normal blood glucose levels were then randomly allocated to each of four experimental groups (5 rats/group). The control group was fed regular laboratory rat chow (standard diet) consisting of $58.1 \%$ wheat flour, $5.8 \%$ corn flour, $7.0 \%$ ground palm nut extract, $11.6 \%$ ground cotton nuts, $5.8 \%$ powdered bone and $11.7 \%$ ground smoked fish. The other three groups were placed on experimental diets, consisting of the standard diet enriched with 35,50 or 65 $\%(\mathrm{w} / \mathrm{w})$ sucrose, respectively (hereafter referred to as sucrose diets). Blood glucose levels were determined for all animals weekly during the 8-week diet period.

\section{Glucose tolerance test}

After 2 weeks on assigned diets, fasting blood glucose levels were determined in control and $50 \%$ sucrose-fed animals. These animals were then orally challenged with $3 \mathrm{~g}$ glucose $/ \mathrm{kg}$ and fasting blood glucose levels determined $30 \mathrm{~min}, 1$ and $2 \mathrm{~h}$ after glucose administration.

\section{Assessment of hypoglycaemic effect of single dose of drugs}

Whole capillary blood glucose levels were determined using a blood glucose spectrophotometer, after an overnight fast. Glucose concentration was measured at time $0 \mathrm{~h}$, i.e., just before administration of the drugs and then at 30 min intervals for $24 \mathrm{~h}$ after drug administration to the groups which received either tolbutamide $(50 \mathrm{mg} / \mathrm{kg})$ or 50 $\mathrm{mg} / \mathrm{kg}$ of (MEBF). For the group which received metformin (38 $\mathrm{mg} / \mathrm{kg})$, blood glucose level was measured after 2, 4, 6, 12,
18 and $24 \mathrm{~h}$ post-treatment. Animals which received insulin (4 $\mathrm{U}$ ) were tested before insulin administration and also $2 \mathrm{~h}$ after insulin administration.

\section{Hypoglycemic and lipid-lowering effects of MEBF}

The animals which showed glucose intolerance after the 8-week dietary period were used for this experiment. Ten of these rats were maintained on $50 \%$ sucrose enriched diet and allocated to one of the two groups - 5 to the control group which received no treatment and 5 to the group treated daily for 6 days with MEFB (50 $\mathrm{mg} / \mathrm{kg}$ ). Serum glucose concentration, triglycerides and total cholesterol were determined before treatment and after 6 days of treatment after a $12 \mathrm{~h}$ fast. Briefly, serum total cholesterol, HDL cholesterol and triglycerides levels were measured in animals enzymatically using Cobas Mira $S$ analyzer with kits purchased from Biolabo (France). LDL-choloesterol was calculated from concentrations of total cholesterol, HDL cholesterol and triglycerides according to Friedewald [16].

\section{Measurement of insulin secretion}

Pancreatic islet cells from NMRI mice (Charles River, Sulzfeld, Germany) were used for these experiments. Mice were sacrificed by inhalation of excess $\mathrm{CO}_{2}$ and batches of 5 pancreatic islets isolated microscopically and incubated for $60 \mathrm{~min}$ at $37{ }^{\circ} \mathrm{C}$ with 3 or $15 \mathrm{mM}$ glucose. The incubation medium (pH 7.4) contained (in $\mathrm{mMol} / \mathrm{l}): 122 \mathrm{NaCl}, 4.8 \mathrm{KCl}, 2.5 \mathrm{CaCl}_{2}, 1.1$ $\mathrm{MgCl}_{2}, 10$ (4-(2-Hydroxyethyl)piperazine-1ethanesulfonic acid (HEPES), as well as 0.5 $\%$ bovine serum albumin. The plant extract was added at different concentrations in the presence of 3 or $15 \mathrm{mM}$ glucose. The amount of insulin secreted was determined by radioimmunoassay using rat insulin (Crystal Chem. Inc., USA) as standard. 


\section{Statistical analysis}

GraphPad Instat was used to carry out oneway analysis of variance (ANOVA) followed by Tukey-Kramer Multiple Comparisons Test. For data on insulin secretion, multiple comparisons were made by ANOVA followed by Student-Newman-Keuls test. The results are expressed as mean \pm standard error. A $p$ value of $<0.05$ was considered significant.

\section{RESULTS}

\section{Effect of diet on glucose tolerance}

Baseline fasting blood glucose levels in normoglycemic rats were between 45 - 52 $\mathrm{mg} / \mathrm{dL}$. Sucrose diets induced significant increases in the mean blood glucose concentration. Animals fed $35 \%$ and $50 \%$ sucrose showed significant $(p<0.05)$ increases in blood glucose levels from week 5 while animals fed $65 \%$ sucrose showed significant $(p<0.05)$ increase in blood sugar levels only during weeks 2 and 6 (Table 1). Animals fed $50 \%$ sucrose diet showed mild levels of hyperglycaemia during the first week of the diet. Although this hyperglycaemia resolved during week 2 week on this diets, the oral glucose tolerance test indicated that there was an impaired glucose tolerance in these animals (Table 2). Animals on sucrose diets had higher glucose levels which remained significantly higher beyond 2 hours after the glucose challenge.

\section{Hypoglycaemic effect of single dose of extract and reference drugs}

The hypoglycaemic activity of porcine insulin (4 U/rat) on sucrose-treated (50\%) glucoseintolerant rats is shown in Table 3. Insulin significantly $(p<0.01)$ reduced blood glucose levels in both normoglycemic and sucrosefed, glucose-intolerant animals.

In normoglycaemic rats, insulin reduced glycaemia by $64.5 \%$, compared to $52.3 \%$ in sucrose-fed rats (Table 3 ). Insulin therefore achieved a better hypoglycaemic effect $2 \mathrm{~h}$ after administration compared to tolbutamide (28 \%), metformin (7\%) and MEBF (- $0.3 \%)$ during a similar period. In $50 \%$ sucrose-fed glucose intolerant rats, tolbutamide induced rapid onset but short lasting hypoglycaemic effects compared to metformin whose effects were of a later onset but more long lasting. Similarly, hypoglycaemic effects of MEBF were of a late onset though it lasted for over 6 hours (Fig. 1).

Table1: Fasting blood glucose concentration (mean $\pm \mathrm{SD}, \mathrm{n}=5$ ) of 6-week old Wistar rats fed with 35,50 and $65 \%$ sucrose-enriched diets for 8 weeks.

\begin{tabular}{|c|c|c|c|c|}
\hline \multirow[b]{2}{*}{ Weeks } & \multicolumn{4}{|c|}{ Fasting blood glucose level (mg/dL) } \\
\hline & Control & $35 \%^{a}$ & $50 \%$ a & $65 \%^{a}$ \\
\hline 0 & $48.5 \pm 0.6$ & $48.0 \pm 1.9$ & $47.5 \pm 2.2$ & $51.3 \pm 1.4$ \\
\hline 1 & $48.3 \pm 0.3$ & $58.0 \pm 1.4$ & $65.0 \pm 2.3^{*}$ & $63.3 \pm 1.8^{*}$ \\
\hline 2 & $47.3 \pm 0.2$ & $44.5 \pm 0.2$ & $47.8 \pm 1.7$ & $45.3 \pm 0.9$ \\
\hline 3 & $48.0 \pm 1.4$ & $59.3 \pm 3.1$ & $50.3 \pm 3.6$ & $45.0 \pm 0.4$ \\
\hline 4 & $48.5 \pm 1.6$ & $49.0 \pm 1.0$ & $58.8 \pm 1.7$ & $53.3 \pm 1.7$ \\
\hline 5 & $47.0 \pm 1.0$ & $60.0 \pm 2.1^{*}$ & $57.5 \pm 2.6$ & $58.3 \pm 2.8$ \\
\hline 6 & $52.0 \pm 1.9$ & $69.3 \pm 4.2^{*}$ & $64.8 \pm 3.0^{*}$ & $64.5 \pm 8.2^{*}$ \\
\hline 7 & $51.5 \pm 0.6$ & $63.3 \pm 3.4^{*}$ & $62.5 \pm 4.3^{*}$ & $58.8 \pm 1.1$ \\
\hline 8 & $48.8 \pm 1.6$ & $60.0 \pm 1.1^{*}$ & $60.0 \pm 2.4^{*}$ & $58.3 \pm 4.2$ \\
\hline
\end{tabular}

Table 2: Mean whole blood glucose concentration (mean $\pm \mathrm{SD}, \mathrm{n}=5$ ) after oral glucose $(3 \mathrm{~g} / \mathrm{kg}$ ) challenge. Sucrose fed animals had been on the $50 \%$ sucrose diet for 2 weeks.

\begin{tabular}{lll}
\hline Time (h) & \multicolumn{2}{c}{ Blood glucose (mg/dL) } \\
\cline { 2 - 3 } & Control rats & Sucrose-fed rats \\
\hline 0 & $53.7 \pm 0.8$ & $60.0 \pm 1.0$ \\
0.5 & $72.0 \pm 0.5$ & $75.8 \pm 5.3$ \\
1.0 & $76.7 \pm 2.0$ & $86.4 \pm 8.5^{\star}$ \\
2.0 & $66.7 \pm 1.4$ & $75.5 \pm 3.0^{*}$ \\
\hline
\end{tabular}

${ }^{*} p<0.05$

Effect of $50 \%$ sucrose diet on fasting blood glucose and lipid levels

The mean serum glucose level of the sucrose-fed rats was $167 \pm 19 \mathrm{mg} / \mathrm{dL}$, while a value of $120.7 \pm 5.7 \mathrm{mg} / \mathrm{dL}$ was obtained for their age, sex and weight matched controls 
Table 3: Hypoglycaemic effect of porcine insulin (4 U/rat, s.c.) in $50 \%$ sucrose-fed and control rats after 12 $\mathrm{h}$ of fasting

\begin{tabular}{ccccc}
\hline Time & \multicolumn{2}{c}{ Control } & \multicolumn{2}{c}{ Sucrose fed rats } \\
\hline (h) & $\begin{array}{c}\text { Blood glucose } \\
(\mathbf{m g} / \mathbf{d L})\end{array}$ & $\begin{array}{c}\text { Reduction in blood } \\
\text { glucose }(\%)\end{array}$ & $\begin{array}{c}\text { Blood glucose } \\
(\mathbf{m g} / \mathbf{d L})\end{array}$ & $\begin{array}{c}\text { Reduction in blood } \\
\text { glucose (\%) }\end{array}$ \\
\hline 0 & $46.7 \pm 1.4$ & - & $73.3 \pm 4.0^{*}$ & - \\
2 & $16.7 \pm 0.3^{*}$ & 64.5 & $35.0 \pm 0.1^{*}$ & 52.3 \\
\hline${ }^{*} p<0.05, \mathrm{n}=5$ & & & &
\end{tabular}

fed standard diet (Fig 2a). Total serum cholesterol level was significantly higher $(p<$ 0.05 ) in sucrose-fed rats than in control rats, while serum triglyceride levels were $280.7 \pm$ 23.1 and $169 \pm 17.1 \mathrm{mg} / \mathrm{dL}(p<0.05)$ in $50 \%$ sucrose-fed and control rats, respectively. The $50 \%$ sucrose diet significantly $(p<0.05)$ increased blood glucose, serum triglyceride and total cholesterol levels

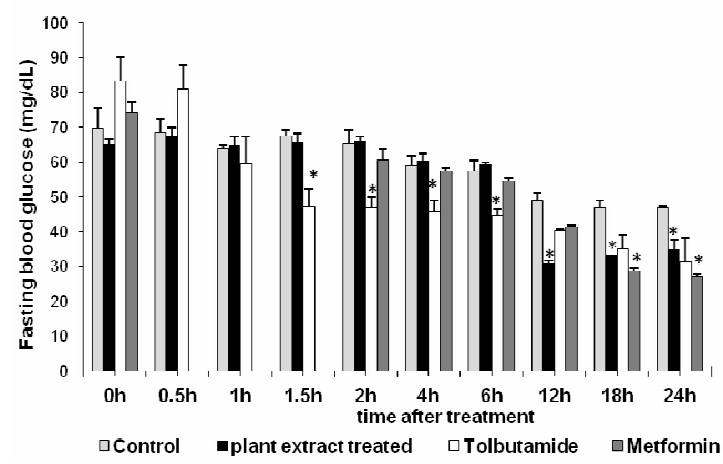

Fig 1: Hypoglycaemic effect of MEBF, tolbutamide and metformin in $50 \%$ sucrose-fed rats after an overnight fast; * $p<0.05$ compared to control, $\mathrm{n}=$ 5.

\section{Effect of 6-day treatment with MEBF on blood glucose and lipid levels}

After 6 days of oral MEBF treatment (50 $\mathrm{mg} / \mathrm{kg} /$ day), fasting blood glucose levels in 50 $\%$ sucrose-fed rats decreased significantly ( $p$ $<0.05$ ) to levels similar to those observed in control animals (126.4 \pm 2.9 versus 167.7 $\mathrm{mg} / \mathrm{dL} \pm 13$ for control). Sucrose-fed rats treated with MEBF significantly $(p<0.05)$ reduced serum triglyceride and total cholesterol relative to control values. Although both triglyceride and total cholesterol levels were significantly reduced by MEBF, post-treatment levels were not different from pre-treatment levels in control animals (Fig 2b).
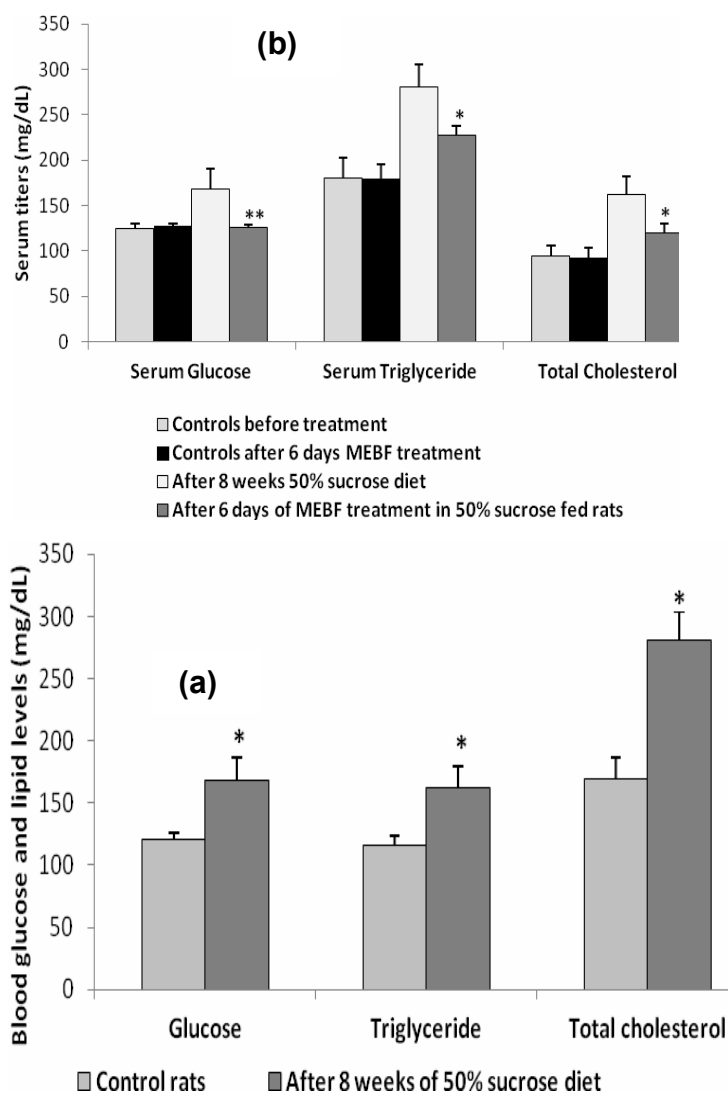

Fig 2: (a) Effect of sucrose-enriched diet on blood glucose, triglyceride and total cholesterol levels of rats after 8 weeks on $50 \%$ sucrose diet; (b) Effect of 6-day MEBF treatment on fasting blood glucose level, serum triglyceride and serum total cholesterol levels in $50 \%$ sucrose-fed animals, compared to control animals; ${ }^{*} p<0.05,{ }^{* *} p<0.01, \mathrm{n}=5$.

Trop J Pharm Res, October 2012;11 (5): 763 


\section{Effect of MEBF extract on insulin secretion}

MEBF, at all dose levels tested, did not induce any significant effect $(p<0.05)$ on insulin secretion.

\section{DISCUSSION}

The results presented demonstrate that rats fed sucrose-rich diets for 8 weeks developed higher fasting blood glucose concentrations. After 2 weeks of ingesting sucrose-enriched diet, the rats showed intolerance to glucose as indicated by the oral glucose tolerance test. Blood glucose levels were significantly higher from the $5^{\text {th }}$ week of sucrose enriched diet, indicating that the impairment of glucose homeostasis is dependent on the duration of exposure to large amounts of sucrose.

When sucrose is consumed, it is broken down to glucose and fructose. Absorbed fructose is converted to lipogenic precursors leading to increase in plasma triglyceride levels $[17,18]$. Our results show that at the end of the 8-week diet period, total cholesterol and triglyceride levels were significantly higher in sucrose-fed rats, compared to control. High fructose diets are associated with increased serum triglyceride [19] and total cholesterol [18] levels. Longterm effects of fructose administration include significant lipotoxicity and hepatic insulin resistance which may eventually lead to a more generalized insulin resistance [20,21]; this was reflected by the significantly higher blood glucose levels in sucrose-fed animals.

Unlike glucose, fructose does not induce the release of insulin or leptin, both of which are necessary for glucose handling [19]. Importantly, Wei et al [22] reported that fructose administration may cause oxidative stress leading to the release of reactive oxygen species which, in turn, may be associated with impaired insulin signalling. This observation is in agreement with our findings which show that sucrose-fed rats had higher blood glucose levels when challenged with oral glucose, indicating impairment in glucose handling mechanisms. The administration of insulin to sucrose-fed rats induced a smaller glucose lowering effect compared to control, suggesting that the sucrose-fed rats had developed impaired response to insulin action. Consistent with this observation, metformin, which acts by increasing insulin-mediated glucose uptake by cells [23], failed to show significant hypoglycaemic activity in sucrose-fed animals until $18 \mathrm{~h}$ post-metformin administration.

MEBF extract exhibited significant hypoglycaemic activity in sucrose-fed, glucose-intolerant rats compared to control rats, indicating that this extract may contain metabolites with anti-diabetic properties. Cholesterol as well as triglyceride levels were also decreased in these rats compared to untreated animals. These two observations suggest that $B$. ferruginea leaf extract lowers blood glucose concentration by improving insulin sensitivity and not by stimulating insulin secretion.

\section{CONCLUSION}

The leaf extract of Bridelia ferruginea exhibited hypoglycaemic effects in sucroseinduced glucose intolerant rats as well as improved lipid profiles. However, further studies are required to ascertain if these findings can be translated to applications.

\section{ACKNOWLEDGEMENT}

This work was supported by the IFS/OPCW (grant no. F/3336-1 to Dr Njamen) and the Walter Sisulu Institutional Research Fund. We wish to thank Mr Nana Victor (National Herbarium, Yaoundé - Cameroon) for his assistance with ethnobotanical survey and collection of the plant material.

\section{REFERENCES}

1. Wild S, Roglic G, Green A, Sicree R, King H. Global prevalence of diabetes: estimates for the year 2000 and projections for 2030. Diabetes Care 2004; 27: 1047-1053.

Trop J Pharm Res, October 2012;11 (5):764 
2. Kumar S, Narwal S, Kumar V, Prakash O. Glucosidase inhibitors from plants: a natural approach to treat diabetes. Pharmacogn Rev 2011; 5: 19-29.

3. Huang BW, Chiang MT, Yao HT and Chiang W. The effect of high-fat and high-fructose diets on glucose tolerance and plasma lipid and leptin levels in rats. Diabetes Obes Metab 2004; 6: 120-126.

4. Oron-Herman $M$, Kamari $Y$, Grossman $E$, Yeger $H$, Peleg E, Shabtay Z, Shamiss A, Sharabi Y. Metabolic syndrome: comparison of the two commonly used animal models. Am J Hypertens 2008; 21: 1019-1022.

5. Elliott SS, Keim NL, Stern JS, Teff K, Havel PJ. Fructose, weight gain, and the insulin resistance syndrome. Am J Clin Nutr 2002; 7: 911-922.

6. Bray GA, Nielsen SJ, Popkin BM. Consumption of high-fructose corn syrup in beverages may play a role in the epidemic of obesity. $A m \mathrm{~J}$ Clin Nutr 2004; 7 9: 537-543.

7. Hu FB. Globalization of diabetes - The role of diet, lifestyle and genes. Diabetes Care 2011; 34: 1249-1257.

8. Ampofo O. The practice of phytotherapy in Ghana. In: Sofowora EA (Ed.) African Medicinal Plants. University of Ife Press, Ile-Ife, 1979; $p$ 67.

9. Iwu MM. Anti-diabetic properties of Bridelia ferruginea leaves. Planta Medica 1980; 39: 247.

10. Talla E, Njamen D, Djoulde DR, Tatsadjeu $L$, Tantoh D, Mbafor JT, Fomum ZT Antimicrobial activity of Bridelia ferruginea leaves extracts. Fitoterapia 2002; 73: 343-345.

11. Olajide OA, Makinde JM, Okpako DT, Awe SO. Studies on the anti-inflammatory and related pharmacological properties of the aqueous extract of Bridelia ferruginea stem bark. J Ethnopharmacol 2000; 71: 153-160.

12. Onunkwo GC, Akah PA, Udeala OK. Studies on Bridelia ferruginea leaves. Stability and hypoglycemic actions of the leaf extract tablets. Phytopther Res 1996; 10: 418-420.

13. Rashid MA, Gustafson KR, cardelina JH, Boyd MR. A new podophyllotoxin derivative from Bridelia ferruginea. Nat Prod Lett 2000; 14: 285-292.

14. Cimanga $K$, Ying L, De Bruyne T, Apers $S$, Cos $P$, Hermans, Bakana $P$, Tona $L$, Kambu $K$, Kalenda DT, Pieters L, Berghe DV, Vlietinck
AJ. Radical scavenging and xanthine oxidase inhibitory activity of phenolic compounds from Bridelia ferruginea stem bark. J Pharm \& Pharmacol 2001; 53: 757-761.

15. EMBO (European Molecular Biological Organization. Revision of the EC directive on the welfare of research animals - An advance briefing 2005. [cited $2011 \mathrm{Feb}$ 27]. Available from: http://www.informatiedierproeven.nl/files/ pdf/Artikelen/Animals\%20EC\%20directive\%20 B8.pdf

16. Friedewald WT, Levy RI, Freidrickson DS. Estimation of the concentration of low-density lipoprotein in plasma, without use of preparative ultracentrifuge. Clin Chem 1927; 18: 499-502

17. Dekker MJ, Su Q, Baker C, Rutledge AC, Adeli K. Fructose: a highly lipogenic nutrient implicated in insulin resistance, hepatic steatosis and the metabolic syndrome. Am J Physiol Endocrinol Metab 2010; 299: E685-E694.

18. Chong MF, Fielding BA, Frayn KN. Mechanisms for the acute effect of fructose on postprandial lipemia. Am J Clin Nutr 2007; 85: 1511-1520.

19. Stanhope KL, Havel P. Endocrine and metabolic effects of consuming beverages sweetened with fructose, glucose, sucrose or highfructose corn syrup. Am J Clin Nutr 2008; 88: 17335-17375.

20. Tappy L, Lê KA. Metabolic effects of sweetened beverages: pathophysiology and mechanistic insights. Off J Inter Chair Cardiometab Risk 2010; 3: 13-18.

21. Stanhope KL, Schwarz JM, Keim NL, Griffen SC, Bremer AA, Graham JL, Hattcher B, Cox CL, Dyachenko A, Zhang $W$ et al. Consuming fructose-sweetened, not glucose-sweetened beverages increases visceral adiposity and lipids and decreases insulin sensitivity in overweight/obese humans. J Clin Invest 2009; 119: 1322-1334.

22. Wei $Y$, Wang $D$, Pagliassotti MJ. Fructose selectively modulates c-jun $N$-terminal kinase activity and insulin signaling in rat primary hepatocytes. J Nutr 2005; 135: 1642-1646.

23. Parakhia RA, Ouyang J, Ochs RS. A new mechanism of action for metformin. FASEBJ 2009; 23: suppl. 856.16 